\title{
Acute Paediatric Mastoiditis in the UK Before and During the COVID-19 Pandemic: A National Observational Study
}

Matthew Smith ${ }^{1}$, G. Huw Jones ${ }^{2}$, John Hardman ${ }^{3}$, Jaya Nichani ${ }^{4}$, sadie khwaja ${ }^{5}$, . INSERT COLLABORATOR LIST HERE ${ }^{6}$, Iain Bruce ${ }^{4}$, and Peter Rea ${ }^{7}$

\author{
${ }^{1}$ Salford Royal Hospitals NHS Trust \\ ${ }^{2}$ Gloucestershire Hospitals NHS Foundation Trust \\ ${ }^{3}$ Royal Marsden Hospital \\ ${ }^{4}$ Royal Manchester Children's Hospital \\ ${ }^{5}$ Stepping Hill Hospital \\ ${ }^{6}$ INTEGRATE UK Acute Paediatric Mastoiditis Audit Collaborators \\ ${ }^{7}$ University Hospitals of Leicester NHS Trust
}

September 25, 2021

\begin{abstract}
Objectives To explore the impact of COVID-19 on the management and outcomes of acute paediatric mastoiditis across the UK. Design National retrospective and prospective audit Setting 48 UK secondary care ENT departments Participants Consecutive children aged 18 years or under, referred to ENT with a clinical diagnosis of mastoiditis. Main outcome measures Cases were divided into: Period 1 (01/11/19-15/03/20) before the UK population were instructed to reduce social contact, and Period 2 (16/03/20-30/04/21), following this. Periods $1 \& 2$ were compared for population variables, management and outcomes. Secondary analyses compared outcomes by primary treatment (medical/needle aspiration/surgical). Results 286 cases met criteria (median 4 per site, range 0-24). 9.4 cases were recorded per week in period 1 versus 2.0 in period 2, with no winter increase in cases in Dec 2020-Feb 2021. Patient age differed between period $1 \& 2$ (3.2 Vs 4.7 years respectively, p $<0.001$ ). 85\% of children in period 2 were tested for COVID-19 with a single positive test. In period 2 cases associated with P. aeruginosa significantly increased. $48.6 \%$ of children were scanned in period 1 vs $41.1 \%$ in period 2 . Surgical management was used more frequently in period $1(43.0 \%$ Vs $24.3 \%, \mathrm{p}=0.001)$. Treatment success was high, with failure of initial management in $6.3 \%$, and 30-day re-admission for recurrence in $2.1 \%$. The adverse event rate ( $15.7 \%$ overall) did not vary by treatment modality or between periods $1 \& 2$. Conclusion The COVID-19 pandemic led to a significant change in the presentation and case-mix of acute paediatric mastoiditis in the UK.
\end{abstract}

\section{Hosted file}

Mastoiditis_before \& during COVID_manuscript_1.2.docx available at https://authorea.com/ users/436125/articles/538676-acute-paediatric-mastoiditis-in-the-uk-before-and-duringthe-covid-19-pandemic-a-national-observational-study

\section{Hosted file}

Mastoiditis audit_Table 1.docx available at https://authorea.com/users/436125/articles/ 538676-acute-paediatric-mastoiditis-in-the-uk-before-and-during-the-covid-19-pandemic-anational-observational-study

\section{Hosted file}


Mastoiditis audit_Table 2.docx available at https://authorea.com/users/436125/articles/ 538676-acute-paediatric-mastoiditis-in-the-uk-before-and-during-the-covid-19-pandemic-anational-observational-study

\section{Hosted file}

Mastoiditis audit_Table 3.docx available at https://authorea.com/users/436125/articles/ 538676-acute-paediatric-mastoiditis-in-the-uk-before-and-during-the-covid-19-pandemic-anational-observational-study
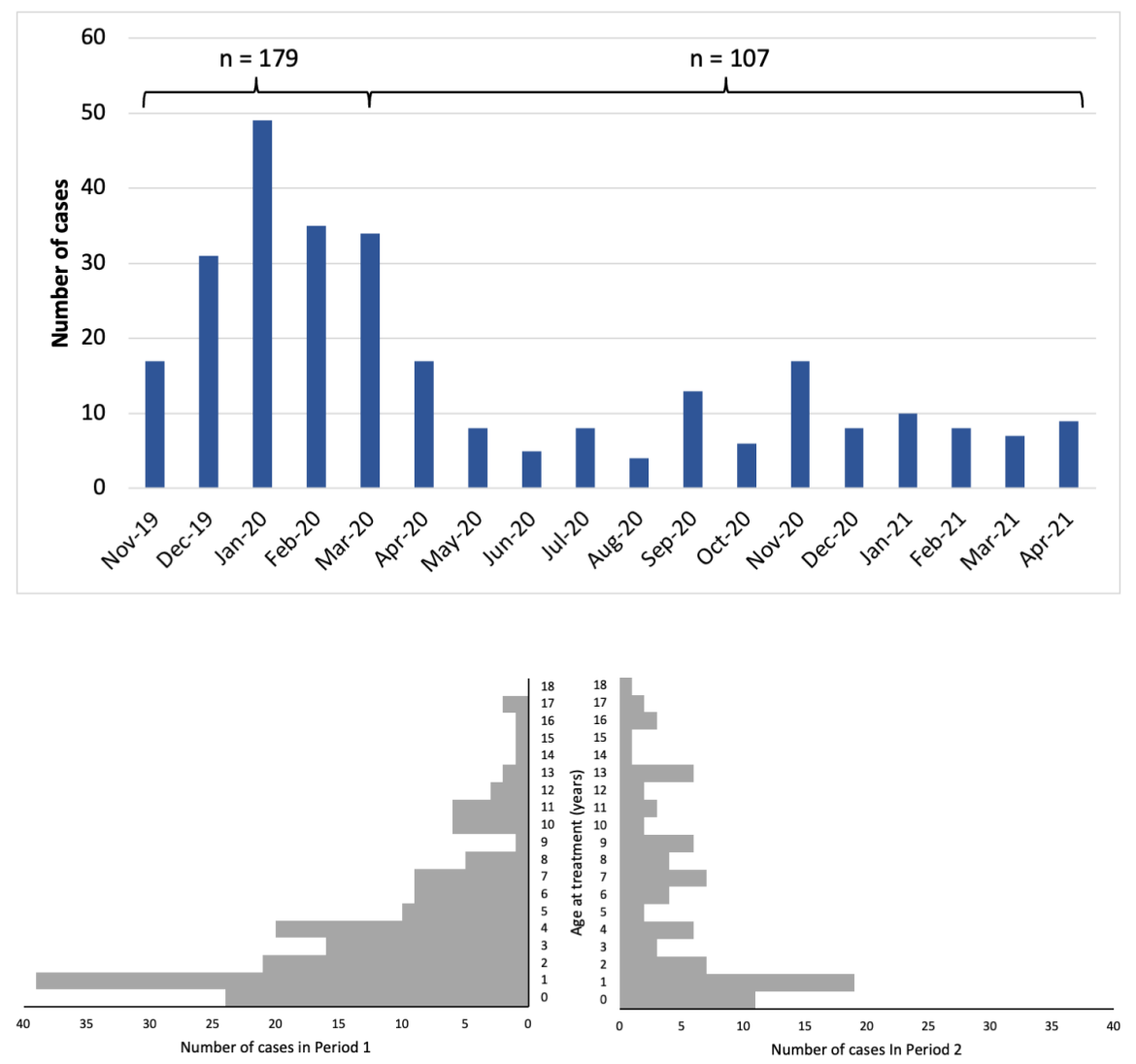


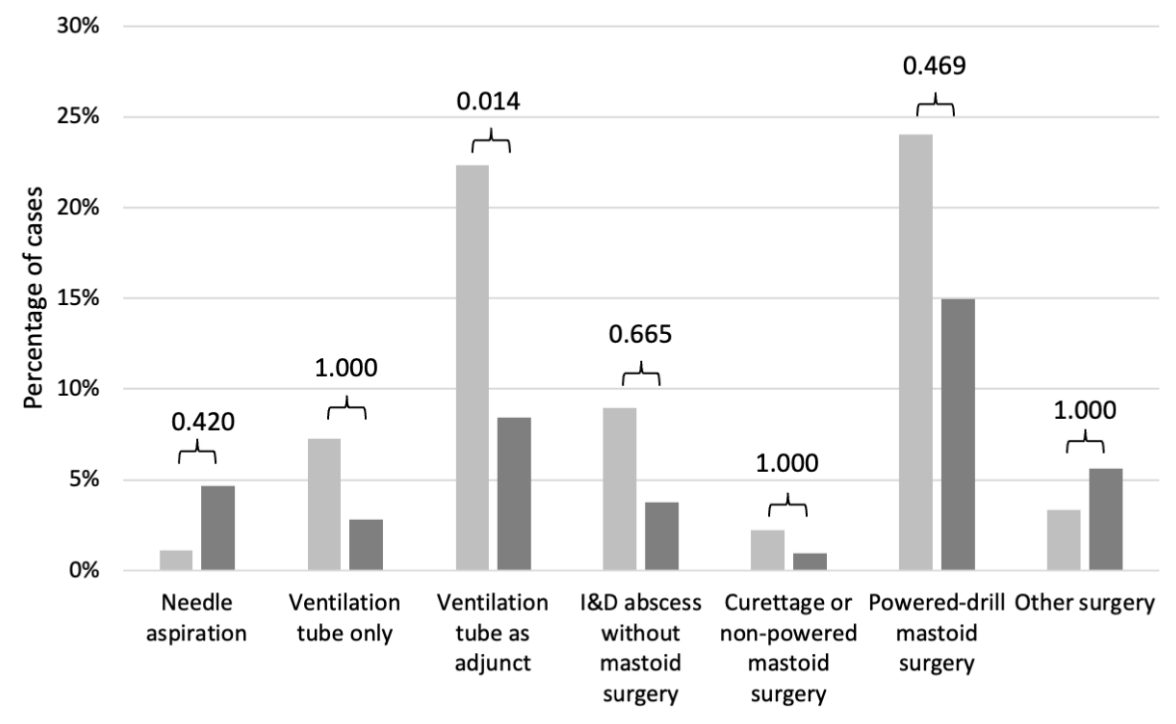

